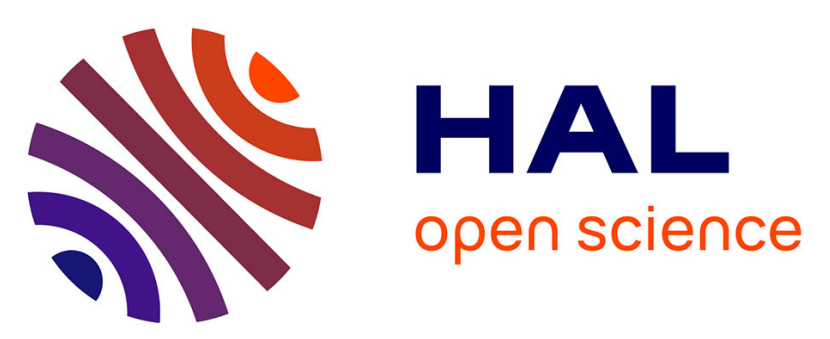

\title{
Incoherent Broad Band Cavity Enhanced Absorption Spectroscopy for simultaneous trace measurements of NO2 and NO3 with a LED source
}

Irene Ventrillard-Courtillot, Ella Sciamma O'Brian, Samir Kassi, Guillaume Méjean, Daniele Romanini

\section{To cite this version:}

Irene Ventrillard-Courtillot, Ella Sciamma O'Brian, Samir Kassi, Guillaume Méjean, Daniele Romanini. Incoherent Broad Band Cavity Enhanced Absorption Spectroscopy for simultaneous trace measurements of NO2 and NO3 with a LED source. Applied Physics B - Laser and Optics, 2010, 101, pp.661-669. 10.1007/s00340-010-4253-x . hal-00562603

\section{HAL Id: hal-00562603 \\ https://hal.science/hal-00562603}

Submitted on 3 Feb 2011

HAL is a multi-disciplinary open access archive for the deposit and dissemination of scientific research documents, whether they are published or not. The documents may come from teaching and research institutions in France or abroad, or from public or private research centers.
L'archive ouverte pluridisciplinaire HAL, est destinée au dépôt et à la diffusion de documents scientifiques de niveau recherche, publiés ou non, émanant des établissements d'enseignement et de recherche français ou étrangers, des laboratoires publics ou privés. 


\title{
Incoherent Broad Band Cavity Enhanced Absorption Spectroscopy for simultaneous trace measurements of $\mathrm{NO}_{2}$ and $\mathrm{NO}_{3}$ with a LED source
}

\author{
I. Ventrillard-Courtillot, E. Sciamma O’Brien, S. Kassi, G. Méjean, D. Romanini \\ Laboratoire de Spectrométrie Physique, CNRS UMR5588, Université J. Fourier de Grenoble, Saint Martin d'Hères, France \\ fax: (33)4 76635495 \\ Mailto: irene.ventrillard@ujf-grenoble.fr
}

September 16, 2010

\begin{abstract}
In the past decade, due to a growing awareness of the importance of air quality and air pollution control, many diagnostic tools and techniques have been developed to detect and quantify the concentration of pollutants such as $\mathrm{NO}_{x}, \mathrm{SO}_{x}, \mathrm{CO}$, and $\mathrm{CO}_{2}$. We present here an Incoherent Broad-Band Cavity-Enhanced Spectroscopy (IBB-CEAS) setup which uses a LED emitting around $625 \mathrm{~nm}$ for the simultaneous detection of $\mathrm{NO}_{2}$ and $\mathrm{NO}_{3}$. The LED light transmitted through a high finesse optical cavity filled with a gas sample is detected by a low resolution spectrometer. After calibration of the spectrometer with a $\mathrm{NO}_{2}$ reference sample, a linear multicomponent fit analysis of the absorption spectra allows for simultaneous measurements of $\mathrm{NO}_{2}$ and $\mathrm{NO}_{3}$ concentrations in a flow of ambient air. The optimal averaging time is found to be on the order of $400 \mathrm{~s}$ and appears to be limited by the drift of the spectrometer. At this averaging time the smallest detectable absorption is $2 \times 10^{-10} \mathrm{~cm}^{-1}$, which corresponds to detection limits of 600 pptv for $\mathrm{NO}_{2}$ and 2 pptv for $\mathrm{NO}_{3}$. This compact and low cost instrument is a promising diagnostic tool for air quality control in urban environments.
\end{abstract}

Key words: environmental monitoring, $\mathrm{NO}_{2}, \mathrm{NO}_{3}$, absorption spectroscopy, light emitting diodes, cavity enhanced absorption, high-finesse cavities

PACS:

0\%.88. $+y$ Instruments for environmental pollution measurements

07.60.Rd Visible and ultraviolet spectrometers

42.60.Da Resonators, cavities, amplifiers

\section{Introduction}

Some nitrogen oxides $\left(\mathrm{NO}_{x}\right)$ are highly reactive and have an impact on the environment even when present in the atmosphere at trace concentration levels. These radicals act as oxidants and play a crucial role in atmospheric chemistry since they are involved in the ozone cycle and in several photochemical reactions. Numerous investigations have been centered on the understanding of these complex interactions $[1,2]$. Although there are natural sources of $\mathrm{NO}_{x}$ such as biological processes in soil, atmospheric discharges, and forest fires, anthropic sources are the most important, with fossil fuel combustion in motor vehicles, building heating, power plants [3]. Urban concentrations of $\mathrm{NO}_{2}$ may exceed $200 \mathrm{ppbv}$ and the average concentration over one year in Paris is 40 ppbv[4]. Monitoring these species is very important since they have a direct impact on the air quality. $\mathrm{NO}_{2}$ is a well-known lung irritant. Moreover, $\mathrm{NO}_{x}$ can be absorbed by water droplets in clouds, converted to $\mathrm{HNO}_{3}$ and produce acid rains [3].

In order to monitor these species, different techniques are used. For $\mathrm{NO}_{2}$, sensitivities better than 100 pptv have been demonstrated by the chemiluminescence technique [5]. However, interferences with other $\mathrm{NO}_{x}$ are possible [6] and this technique requires frequent calibrations. The Long-Path Differential Optical Absorption Spectroscopy (LP-DOAS) technique has also been widely exploited to measure $\mathrm{NO}_{2}$ and $\mathrm{NO}_{3}$ concentrations in the atmosphere, but the resulting measurement are integrated over a gas column of several hundred meters or more $[7,8]$. The differential absorption LIDAR technique is capable of a better spatial resolution. It has been applied to measurements of $\mathrm{NO}_{x}$ concentrations already several years ago $[9,10]$. However its sensitivity is limited by the laser power available to typical values of about 1 ppm.m which for ppbv $\mathrm{NO}_{x}$ detection levels requires integrating over distances of several hundred meters.

Therefore, over the past decade, numerous instruments based on high-finesse cavity techniques have been developed allowing for robust, selective and highly sensitive measurements. Different analyzers based on Light Induced Fluorescence (LIF) [11], Cavity Ring Down 
Spectroscopy (CRDS) [12], Optical Feedback Cavity Enhanced Absorption Spectroscopy (OF-CEAS) [13], cavity-attenuated phase shift spectroscopy [14], Incoherent Broad-Band Cavity-Enhanced Absorption Spectroscopy (IBB-CEAS) [15-21] have been developed. The instrument described here is in the continuity of our previous work [20], based on the IBB-CEAS technique. The setup was developed following the idea of a portable compact device with a LED emitting around $625 \mathrm{~nm}$ coupled into a $0.5 \mathrm{~m}$ long optical cavity. This allows for real time and simultaneous measurement of $\mathrm{NO}_{2}$ and $\mathrm{NO}_{3}$ concentrations with detection limits of respectively $600 \mathrm{pptv}$ and $2 \mathrm{pptv}$, for an optimal $400 \mathrm{~s}$ acquisition time. Relatively compact IBB-CEAS setups based on a LED have been previously reported $[16,18,19,21]$. The lower detection limit reported for $\mathrm{NO}_{3}$ is 2.5 pptv measured around $662 \mathrm{~nm}$ for a $516 \mathrm{~s}$ acquisition time [16]. This is close to our present performance, but it was obtained with an optical cavity of $1.9 \mathrm{~m}$, nearly 4 times in length. Going in the blue spectral region with a LED emitting around $450 \mathrm{~nm}$ and using an optical cavity of $1.5 \mathrm{~m}$, allowed the same group to perform $\mathrm{NO}_{2}$ measurements in ambient laboratory air down to $100 \mathrm{pptv}$ for a $60 \mathrm{~s}$ averaging period [18]. To our knowledge, the only instrument previously developed that allows measurements of both $\mathrm{NO}_{2}$ and $\mathrm{NO}_{3}$ exploits a xenon arc-lamp $(75 \mathrm{~W})$ in the spectral range of $620 \mathrm{~nm}$ to $700 \mathrm{~nm}$ [17]. $\mathrm{NO}_{3}$ detection limit is close to the value reported here ( 4 pptv in a $60 \mathrm{~s}$ acquisition time) while it is more than ten times higher for $\mathrm{NO}_{2}$ (10 ppbv over $\left.60 \mathrm{~s}\right)$. Furthermore, the arc-lamp is coupled to an atmospheric chamber using a $3.82 \mathrm{~m}$ optical cavity, making this set-up a laboratory tool suitable for spectroscopy or measurement of reactive species. As a consequence, the analyzer presented here combines for the first time the advantage of being compact and truly portable, and relatively low cost for spatially and temporally resolved $\mathrm{NO}_{2}$ and $\mathrm{NO}_{3}$ trace measurements with detection limits largely sufficient for air quality control in urban environments.

In this paper, we describe the experimental setup in section 2. Section 3 deals with the real time computation of $\mathrm{NO}_{2}$ and $\mathrm{NO}_{3}$ concentrations, using a linear multicomponent fit of the transmitted light spectrum. $\mathrm{NO}_{2}$ and $\mathrm{NO}_{3}$ measurements are presented and discussed in section 4 and 5 .

\section{Experimental setup}

In the instrument we have developed, the optical setup has the major advantage of being compact and quite simple, as shown in Figure 1. A complete description of the setup has been given previously [20]. Here we only give a brief overview with emphasis on the improvements.

Light emitted from a LED is collimated with a first lens $\mathrm{L}_{1}$ and injected into a high finesse optical cavity. The fraction of light transmitted by the cavity is then

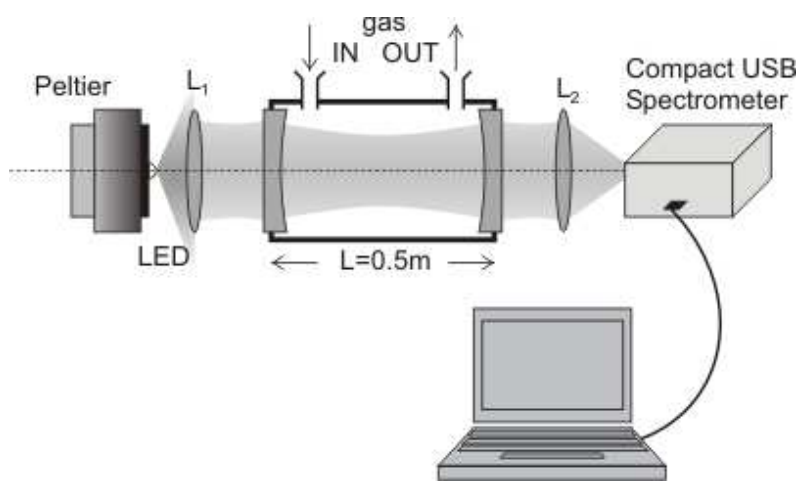

Fig. 1 Schematic of the experimental setup, which is mounted on a $1 \mathrm{~m}$ long aluminum rail. The total weight is less than $10 \mathrm{~kg}$, including the spectrometer and the laptop computer.

focused, using a second lens $\mathrm{L}_{2}$, directly onto the entrance slit of a low resolution spectrometer (EPP2000 Stellar Net). $\mathrm{NO}_{2}$ and $\mathrm{NO}_{3}$ concentrations are computed in real time according to the data analysis detailed in the following section.

In the setup previously described, an optical fiber was connected to the spectrometer. It has since been removed, degrading the spectrometer resolution from about $1.8 \mathrm{~nm}$ to $2.3 \mathrm{~nm}$ FWHM, but largely increasing the light level on the CCD array. This is a major advantage, the short term sensitivity being limited by the photon shot noise limit as reported in section 4. Moreover, a new mirror set with better reflectivity has been used leading to an increased effective path in the absorption cell by a factor of 5; the finesse reaching 20000 . Furthermore the gain in detectivity allowed us to reduce by a factor of two the mirror diameter (half an inch) and consequently significantly reduce the cell volume to get a faster renewal of the sample for a given flow rate in order to minimize memory effects.

The optical cavity consists in two mirrors with $1 \mathrm{~m}$ radius of curvature, placed about $50 \mathrm{~cm}$ apart (but not to the exact confocal distance). The cavity free spectral range $(\sim 300 \mathrm{MHz})$ is already well below the Doppler broadening of the absorption lines composing the dense spectra of $\mathrm{NO}_{2}$ and $\mathrm{NO}_{3}$ (more than $700 \mathrm{MHz}$ FWHM). The mirror reflectivity profile $\mathrm{R}(\lambda)$ in the LED spectral region is about $99.98 \%$. It should be emphasized that, because of this high reflectivity, the confocal configuration is not adapted to make a robust, transportable and inexpensive analyzer, since the cavity length has to be adjusted with a sub-micrometric precision to efficiently improve the cavity transmission [22].

The two lenses $L_{1}$ and $L_{2}$ are chosen to maximize the light flux reaching the $40 \mathrm{~mm}$ diameter parabolic grating of the spectrometer that images the input slit onto the CCD array. The optimum is found to be similar to the configuration where in absence of cavity the LED image would be formed onto the $25 \mu \mathrm{m}$ by $3 \mathrm{~mm}$ entrance slit of the spectrometer. The best configuration is not ob- 
tained when the LED image is close to $25 \mu \mathrm{m}$ because in this case the beam divergence is much larger than the numerical aperture (NA) of the spectrometer fixed by the grating size and its distance from the entrance slit $(\mathrm{NA}=0.15)$. A simple model, in good agreement with the experiment, has shown that the optimal configuration is obtained when the optical beam is focused onto the slit with a divergence that matches the spectrometer's NA. This is valid as far as the LED image is not bigger than the height of the slit. In addition, the maximum coupling efficiency to the cavity is obtained when $\mathrm{L}_{1}$ focuses the beam onto the output mirror of the cavity. The choice of its focal length is a trade-off between the lens distance from the LED which should be kept as short as possible to collect a maximum fraction of the light emitted (high numerical aperture), and a magnification coefficient (equal to $\mathrm{f}_{2} / \mathrm{f}_{1}$ ) that minimizes the losses at the spectrometer slit. The optimum was found for $\mathrm{f}_{1}=20 \mathrm{~mm}$ and $\mathrm{f}_{2}=40 \mathrm{~mm}$.

The LED used is a Luxeon K2, LXK2-PH12. It was chosen for its spectral emission, centered at $625 \mathrm{~nm}$ and possessing a $15 \mathrm{~nm}$ FWHM spanning the strong $\mathrm{NO}_{3}$ absorption bands around $623 \mathrm{~nm}$ together with a few $\mathrm{NO}_{2}$ absorption features as shown in figure 2. This LED emits 60 lumen $(\simeq 260 \mathrm{~mW})$ at $350 \mathrm{~mA}$ of driving current. With the optical setup described above, the CCD saturation level is reached with an integration time of about $400 \mathrm{~ms}$. The LED spectral distribution and intensity are not monitored but a stable power supply is used to avoid any spectral fluctuations that would limit the reproducibility of the CEAS spectra and thus of the concentration measurements. In addition, the LED temperature is stabilized within about $\pm 1 \mathrm{mK}$ using a Peltier cooler and a thermistance placed close to the LED to provide the control signal for a PID servo electronic system. We estimate that the LED emission spectrum is then stable to better than $0.015 \mathrm{~nm}$, while its total intensity drift is measured to be lower than $0.02 \%$ per hour. This intensity stability is reached with the LED soft polymer collimating lens removed.

The mirrors are mounted in vacuum-tight cylindrical holders sealed by two o-rings to a stainless tube. This constitutes the gas cell. The mirror mounts limit the optical clearance to $10 \mathrm{~mm}$ diameter, dimension that was chosen for the tube internal diameter. The gas inlet and outlet are placed close to each mirror to allow a rapid and complete sample renewal. The sample is continuously flown through the cell at atmospheric pressure with a flow rate ranging from 0.25 to $1 \mathrm{~L} / \mathrm{min}$, set by high precision mass flow controllers (MFC). $\mathrm{NO}_{2}$ and $\mathrm{NO}_{3}$ being very reactive, the gas circulation system is made mostly with Teflon (PFA) tubes (with the exception of the stainless steel MFCs valves and the cell itself).

Samples with different $\mathrm{NO}_{2}$ dilution are accurately generated by flow dilution in dry nitrogen of a certified $\mathrm{NO}_{2}$ sample diluted in standard air (Air Liquide, high pressure passivated tank). Our sample is certi-

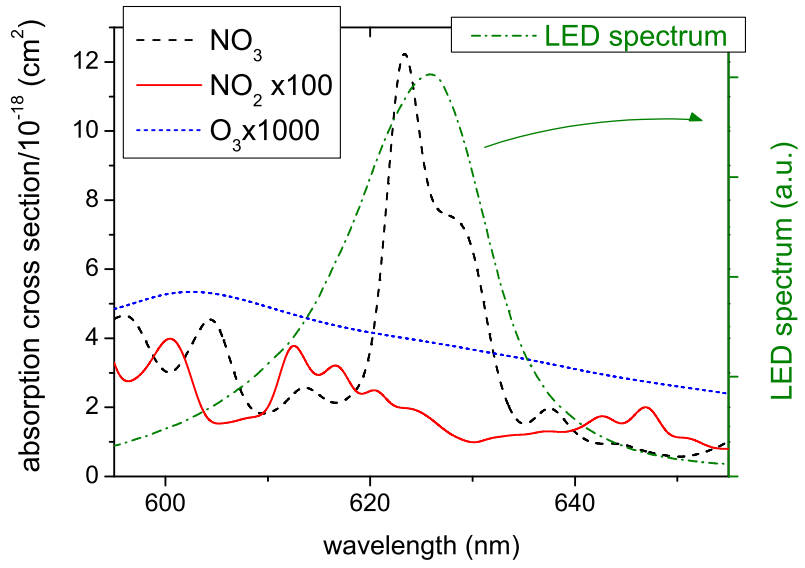

Fig. 2 LED spectrum (right scale) and $\mathrm{NO}_{2}, \mathrm{NO}_{3}$ and $\mathrm{O}_{3}$ absorption cross-sections convoluted with a $2.3 \mathrm{~nm}$ FWHM Gaussian for the spectrometer spectral response function (left scale). Note that for clarity, $\mathrm{NO}_{2}$ and ozone cross sections are multiplied by a factor of 100 and 1000 respectively.

fied to $8.55 \pm 0.17 \mathrm{ppmv}$ within a year. The flow dilution is controlled using two dedicated high precision MFCs with working range being 0.02 to $1 \mathrm{~L} / \mathrm{mn}$ and 0.001 to $0.05 \mathrm{~L} / \mathrm{mn}$. Their accuracy are specified to $0.8 \%$ on the readout value plus $0.2 \%$ of the full scale.

On the other hand, $\mathrm{NO}_{3}$ is too unstable to be stored but can be produced following the reaction:

$$
\mathrm{NO}_{2}+\mathrm{O}_{3} \rightarrow \mathrm{NO}_{3}+\mathrm{O}_{2}
$$

To produce $\mathrm{NO}_{3}$, a flow of about $1 \mathrm{~L} / \mathrm{mn}$ of our reference sample of $\mathrm{NO}_{2}$ diluted in air is sent directly through an ozone generator (OL 100 from Yanco Industries) where the above reaction may occur. Ozone concentration is adjusted by tuning the generator discharge rate. As it was reported, ozone has to be in large excess [23]. This protocol allows the production of only a few ppbv of $\mathrm{NO}_{3}$ in a gas mixture where hundreds of ppmv of $\mathrm{O}_{3}$ remain. The results would likely be similar using air instead of our $\mathrm{NO}_{2}$ calibrated bottle since discharges are known to be efficient sources of $\mathrm{NO}_{x}$ when used with air [3]. However, in our experimental conditions, ozone concentration was so important that no $\mathrm{NO}_{2}$ traces remained or could be detected. Moreover, we suspect the reaction of $\mathrm{NO}_{2}$ and $\mathrm{NO}_{3}$ to mainly generate $\mathrm{N}_{2} \mathrm{O}_{5}$, a species that can not unfortunately be monitored in the present spectral range. Thus, to produce a mixture of $\mathrm{NO}_{2}$ and $\mathrm{NO}_{3}$, a diluted $\mathrm{NO}_{2}$ flow was added at the entrance of the cavity.

Despite a three orders of magnitude stronger $\mathrm{NO}_{3}$ cross section in the spectral range of the LED emission profile (fig. 2), the absorption by the remaining ozone is still dominant. The output of the ozone generator has to be further diluted in dry nitrogen by a factor of 25 to 
lower $\mathrm{O}_{3}$ absorption down to $10 \%$ of the cavity transmittance. That corresponds to few ppmv of remaining $\mathrm{O}_{3}$. Absorption due to the strong $\mathrm{NO}_{3}$ band contributes then to less than $1 \%$ of the total absorption that corresponds to several hundreds of pptv. Unexpectedly, we observed $\mathrm{NO}_{3}$ concentration fluctuations of $10 \%$ within a few seconds.

\section{Data analysis: from spectrograph raw signals to absolute concentrations}

We have developed data analysis software that delivers, in real time and simultaneously, the absolute concentrations of $\mathrm{NO}_{2}$ and $\mathrm{NO}_{3}$ in a gas sample flowing continuously in the optical cavity. This software is based on LabVIEW and includes data acquisition routines from the Stellar Net spectrograph.

Absolute concentrations are inferred from the intensity of LED radiation transmitted by the cavity containing the gas sample $I(\lambda)$, measured by the spectrometer as a function of wavelength. This raw spectrum is processed together with a "reference" spectrum and a "background" spectrum recorded on the same setup as follows. First, to account for the combined spectral profiles of LED emission, cavity mirrors transmission, and spectrometer response, the reference spectrum, $I_{r e f}(\lambda)$, is recorded with a non absorbing dry nitrogen flow. The integration time is set in such a way that the CCD array is close to saturation at the maximum of the LED emission profile. This integration time is then used for all the following measurements. Second, the dark (or background) spectrum, $I_{\text {dark }}(\lambda)$, is recorded with the LED beam blocked to sample the CCD array noise pattern to be subtracted from all other signal spectra (including the reference). In order to improve the signal to noise ratio, reference and background spectra are obtained by averaging several CCD exposures.

The normalized transmitted intensity is then defined by:

$$
s(\lambda)=\frac{I-I_{\text {dark }}}{I_{\text {ref }}-I_{\text {dark }}}
$$

The absorbance of the sample is computed from the following expression $[15,20]$ :

$$
\alpha(\lambda) \simeq \frac{1-s(\lambda)}{s(\lambda)} K(\lambda)
$$

where $K$ depends only on the optical cavity length $L$ and the mirrors reflectivity $R$ :

$$
K(\lambda)=\frac{1-R(\lambda)}{L}
$$

The absorbance given by Eq.(3) is a good approximation of the exact value whose expression can be found in $[15,20]$. Surprisingly, the fractional error is lower than $0.2 \%$ for mirrors having a $99.98 \%$ reflectivity even in the presence of intra cavity losses as high as $90 \%$ per pass, yielding $s=2 \times 10^{-3}$.

In the work presented here, as we used high reflective mirrors $(\mathrm{R} \simeq 99.98 \%)$ it was not possible to derive $R(\lambda)$ from direct transmission measurements using a spectro-photometer. Morever, it would not produce a reliable value for $R$ even for lower reflectivity [20]. A measurement of $R(\lambda)$ by CRDS was not undertaken as it requires a broadly tunable laser source. The solution we have chosen for both its relative simplicity and accuracy, was to calibrate the apparatus using a sample of known absorption spectrum. Let's emphasize that, as already proposed [20], it can be a sample of any known molecule (or a set of molecules) and not necessarily the one to be monitored. This procedure is based on the fact that $K(\lambda)$ may be derived from the measurement of the absorption spectrum $s_{0}$ of a reference sample containing a molecule at known concentration $N_{0}$ and with a known cross section $\sigma_{0}$, according to the following expression:

$$
K(\lambda)=\sigma_{0}(\lambda+\delta \lambda) N_{0} \times \frac{s_{0}(\lambda)}{1-s_{0}(\lambda)},
$$

where $\delta \lambda$ is introduced to correct for a shift of the spectrometer wavelength calibration. In the spectral range of the LED emission (typically 610 to $640 \mathrm{~nm}$ ), $K(\lambda)$ is found to be well approximated by a Gaussian profile. The adjustable parameters of the fitting process are then the center and width of the Gaussian and the wavelength shift $\delta \lambda$.

We have chosen to calibrate the apparatus with $\mathrm{NO}_{2}$ for its highly structured spectrum in the visible range (cf. Fig. 2) and its commercial availability as a stable calibrated sample. Since $\mathrm{NO}_{2}$ is a reactive molecule, it is necessary to passivate the walls of the gas-handling system during a few hours at the first usage of the cell. After passivation, it appeared that to record a reliable calibration spectrum only 20 minutes waiting was enough, using the 8.55 ppmv $\mathrm{NO}_{2}$ sample with a $1 \mathrm{~L} / \mathrm{mn}$ flow. As a $\mathrm{NO}_{2}$ cross section, we use the high resolution absorption spectrum by Voigt et al. [24] convoluted with a $2.3 \mathrm{~nm}$ FWHM Gaussian to account for spectrometer resolution. Although not necessary for the data analysis, the mirrors reflectivity was deduced from $K(\lambda)$ using Eq. (4), and was found to change less than $0.23 \%$ over the $15 \mathrm{~nm}$ FWHM of the LED emission profile. From 610 to $640 \mathrm{~nm}$, an average reflectivity of $99.985 \%$ was deduced, in agreement with the mirrors specification $(99.98 \pm 0.02 \%)$. In addition, this calibration procedure allowed to correct for a spectrometer wavelength shift of about $0.4 \mathrm{~nm}$.

An advantage of this calibration procedure is that the effective cavity finesse, or equivalently the absorption path length, is obtained for the same multi-mode spatial cavity excitation as the one used for the CEAS measurements. A contrario, if a ring down measurement scheme was used to determine these, it would be impossible to establish a simple relationship between a spatially (and possibly spectrally) multi-mode ringdown value and the 
effective cavity finesse. Moreover, a multi-mode ringdown signal is in principle not even an exponential decay. It should be emphasized that our calibration procedure, easy to do in situ, takes into account mirror reflectivity changes, what a more sophisticated laboratory ring down measurement would not. As a consequence, mirrors do not need cleaning as long as the cavity finesse and the transmitted intensity remain large enough to guarantee a given detection limit for trace measurements. The time interval between successive calibrations depends on the amount of dust present in the gas flowing through the cavity, and on the details of the cell construction which may be effective in reducing aerosol deposition on the mirrors surfaces.

After calibrating with a $\mathrm{NO}_{2}$ certified sample, it is then possible to compute the absolute concentration of any molecule of known absorption cross section flowing in the cavity. In our particular case, we aim to simultaneously measure the absolute concentrations of $\mathrm{NO}_{2}$ and $\mathrm{NO}_{3}$ by applying to each measured absorption spectrum, $\alpha(\lambda)$, a standard linear multicomponent fit according to the following expression:

$$
\alpha(\lambda)=\sigma_{N O_{2}}(\lambda) \cdot N_{N_{2}}+\sigma_{N O_{3}}(\lambda) \cdot N_{N O_{3}}+p(\lambda),
$$

where $\sigma_{i}$ are the absorption cross sections convoluted with the spectrometer resolution. The adjustable parameters of the fit are the concentrations $N_{\mathrm{NO}_{2}}$ and $N_{\mathrm{NO}_{3}}$ and the coefficients of a polynomial function $p(\lambda)$. This function is added to account for the baseline distortion that can be induced by calibration artifacts, a shift of the LED spectrum or the presence of unaccounted species with structureless spectrum, e.g. aerosols and ozone (cf. fig 2).

\section{Performance for $\mathrm{NO}_{2}$ measurements}

In order to characterize the linearity of the system and its detection limit we used two mass flow controllers, as already mentioned in section 2 , to produce controlled and stable concentrations in a rather large range starting with our calibrated commercial $\mathrm{NO}_{2}$ mixture $(8.55 \mathrm{ppmv}$ $\pm 2 \%)$ and dry nitrogen.

After some testing, we found that measurements have to be performed with flows higher than $0.25 \mathrm{~L} / \mathrm{mn}$ to avoid long-lasting memory effects. With slower flows, the observed concentration appears to keep drifting over time scales unpractically long, while for larger flows we can obtain stable readings after about 5 minutes. In this study, we thus recorded calibration spectra with the $\mathrm{NO}_{2}$ calibrated mixture flowing at $1 \mathrm{~L} / \mathrm{mn}$. We then acquired spectra of $\mathrm{NO}_{2}$ diluted in dry nitrogen up to 400 times with flows ranging from $0.35 \mathrm{~L} / \mathrm{mn}$ to $1.05 \mathrm{~L} / \mathrm{mn}$. The accessible concentration range and flux values were limited by the working range of the two MFCs. To cover the broadest concentration range, we mostly used the smaller MFC $\left(0.05 \mathrm{~L} / \mathrm{mn}\right.$ full scale) for the $\mathrm{NO}_{2}$ mixture
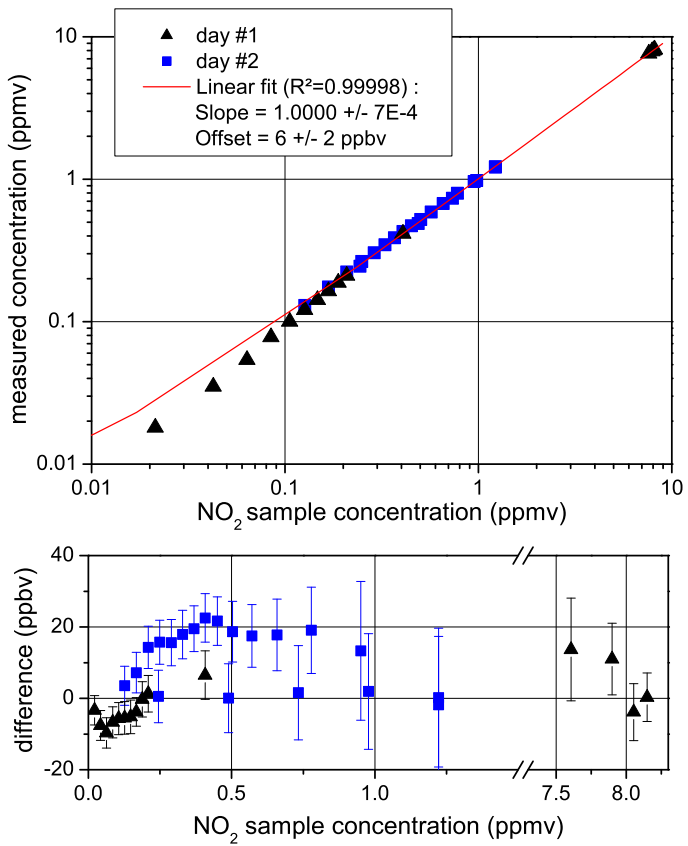

Fig. 3 Upper: Measured $\mathrm{NO}_{2}$ concentration versus calculated sample concentration obtained by dilution of a calibrated sample. Lower: Difference in ppbv between measurement and sample concentration. The error bars correspond to the quadratic sum of the measurements standard deviation and the uncertainty linked to the accuracy of the mass flow controllers used to make the dilution.

and the larger MFC (1 L/mn full scale) for dry nitrogen. We also performed a few measurements switching the two MFCs to produce higher concentrations.

As shown in figure $3, \mathrm{NO}_{2}$ levels obtained from real time data analysis were found to be in agreement with values expected from the dilution factors and the calibrated sample concentration. Each data point represents the $\mathrm{NO}_{2}$ concentration measured after a stable reading was achieved and averaged for $5 \mathrm{~min}$ and $10 \mathrm{~min}$, for the first and second measurement day, respectively. The standard deviation on these values is on the order of $5 \mathrm{ppbv}$ for all measurements, while the uncertainty on the sample concentration due to the accuracy of the MFCs depends on the dilution ratio and remains below $5 \%$ for all concentrations used here. It should also be noted that this set of measurements was recorded over two days using the same reference spectrum, which illustrates the good long-term stability of the calibration. However, as stated above, this stability depends principally upon the rate at which aerosols may accumulate on mirror surfaces and degrade their reflectivity, which factor is independent from the instrument itself as it concerns the sample aerosol content and the way particles are removed from it.

Despite a small offset of $6 \pm 2 \mathrm{ppbv}$, the measured concentrations display deviations below $10 \%$ in the range of 
80 ppbv to 8 ppmv, as shown in figure 3 . The good linearity of the instrument response could thus be verified over two decades of concentration. The spreading of the measurements seems not to be random probably indicating residual memory effects. At concentrations lower than 100 ppbv, measurements fell well below the expected values, indicating losses of $\mathrm{NO}_{2}$. This is due to the fact that, even if these measurements were performed at a total flow higher than $1 \mathrm{~L} / \mathrm{mn}$, the calibrated $\mathrm{NO}_{2}$ sample flow up to the dilution point was actually below $0.02 \mathrm{~L} / \mathrm{mn}$. A different dilution system should be used in the future in order to allow for higher flows of $\mathrm{NO}_{2}$ containing sample at different stages of dilution.

At concentrations higher than $0.5 \mathrm{ppmv}$, deviations were below $4 \%$, which corresponds to the precision of the MFCs. The uncertainty of $2 \%$ on the specified value of the $\mathrm{NO}_{2}$ calibrated sample does only account for a systematic error that would affect the absolute concentration values and represents the ultimate accuracy using the calibration procedure detailed in the previous section.

The minimum absorption detectable with our setup can be estimated by calculating the Allan standard deviation [25]. As shown in figure 4, low and high concentration measurements lead to the same trend. As expected for white noise, the Allan standard deviation initially decreases as the inverse square root of the time and then reaches a minimum value of typically 600 pptv after about $400 \mathrm{~s}$. Using the mean absorption cross section of $\mathrm{NO}_{2}$ between $610 \mathrm{~nm}$ and $640 \mathrm{~nm}\left(2.0 \times 10^{-20} \mathrm{~cm}^{2}\right)$, this minimum concentration can be converted into a minimum absorbance value of $3.2 \times 10^{-10} \mathrm{~cm}^{-1}$. The fitting procedure used to calculate the $\mathrm{NO}_{2}$ concentration is however not sensitive to the continuum of the molecular spectrum, which represents about $35 \%$ of the total $\mathrm{NO}_{2}$ absorption. The minimum absorbance that can be detected is then $2.1 \times 10^{-10} \mathrm{~cm}^{-1}$. To confirm this analysis, we have independently obtained the mean value of the absorbance given by (3) applied to spectra recorded with dry nitrogen flowing in the cavity. In this case the Allan deviation reached a minimum value of $1.9 \times 10^{-10}$ $\mathrm{cm}^{-1}$ within about $200 \mathrm{~s}$.

Is is important to note that the maximum time averaging does not appear to be limited by the stability of the LED spectral emission, neither by the mechanical stability of the setup, but rather by the stability of the spectrometer. Indeed the same averaging time limit of a few hundreds of seconds could be observed in all the different configurations that were tested: with pure nitrogen or with $\mathrm{NO}_{2}$ samples flowing in the cavity; by removing the optical cavity and averaging the LED emission profile between $610 \mathrm{~nm}$ and $640 \mathrm{~nm}$; or even averaging the spectrometer dark current on the same spectral region. It should be noted that the spectrometer drift in the LED spectral region of interest cannot be corrected using the signal delivered by pixels that are not lighted during the experiment (e.g. around 260nm) because the

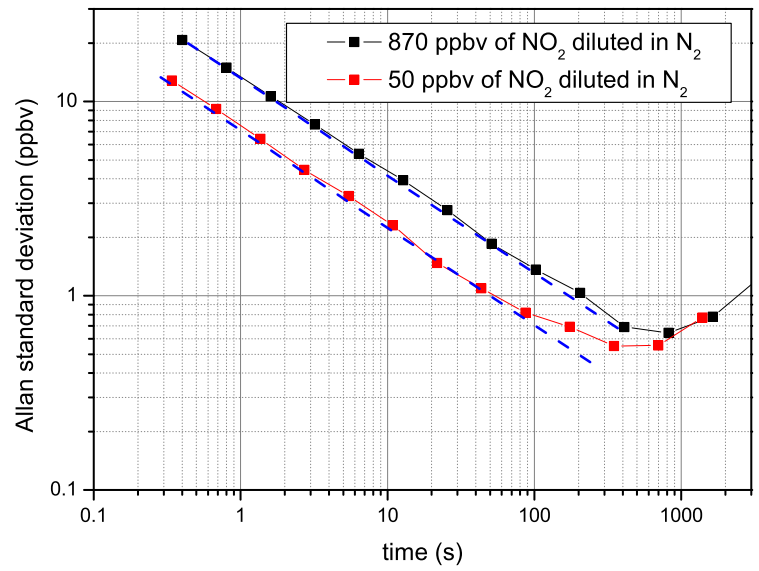

Fig. 4 Allan standard deviation of $\mathrm{NO}_{2}$ concentrations computed using the multilinear fit, for two different concentrations. The dashed lines represent the inverse square root dependence expected for white noise.

dark current of each pixel is different. To improve the stability of the spectrometer, and then the minimum detectable absorption, a temperature stabilization of the spectrometer should be implemented in order to reduce the drift in the CCD array response and the noise of the analog to digital conversion electronics.

The Allan standard deviation at $400 \mathrm{~ms}$ (which corresponds to the "classic" standard deviation of concentration values derived from the fit to spectra averaged over this time) reaches the photon shot noise limit. This is evaluated using the mean number of counts per pixel that is around 3000 and 3500 respectively for $870 \mathrm{ppbv}$ and $50 \mathrm{ppbv} \mathrm{NO}_{2}$ samples (saturation occurs at 4096 counts). Furthermore, the spectrometer has a pixel well depth of 62500 electrons. The relative photon shot noise for one pixel is then respectively $4.7 \times 10^{-3}$ and $4.3 \times 10^{-3}$. We have developed a numerical model to generate a set of spectra derived from one experimental spectrum to which is added a random noise that follows for each pixel a Gaussian statistic with a standard deviation equal to the photon shot noise. The standard deviations of the mean concentration value obtained after fitting the set of spectra are $20 \mathrm{ppbv}$ and $13 \mathrm{ppbv}$ for $\mathrm{NO}_{2}$ concentrations of $870 \mathrm{ppbv}$ and $50 \mathrm{ppbv}$, respectively. These values are in excellent agreement with the Allan standard deviations measured at $400 \mathrm{~ms}$ as shown in figure 4.

\section{$5 \mathrm{NO}_{3}$ measurements and simultaneous measurements of $\mathrm{NO}_{2}$ and $\mathrm{NO}_{3}$}

As explained in section $2, \mathrm{NO}_{3}$ samples cannot be stored at calibrated concentrations and need to be produced in the laboratory from the chemical reaction between $\mathrm{NO}_{2}$ 
and $\mathrm{O}_{3}$ before being injected in the spectrometer cell. The $\mathrm{NO}_{3}$ concentration we obtained this way, however, presented wide fluctuations preventing a long term sensitivity analysis with this species. Nonetheless, the short term detection limit for $\mathrm{NO}_{3}$ is found to be equivalent to that of $\mathrm{NO}_{2}$, as discussed below.

Measurements for each molecules as well as a mixture of the two were taken under the same experimental conditions: 10 spectra were acquired with a $400 \mathrm{~ms}$ integration time and averaged. The $\mathrm{NO}_{2}$ and $\mathrm{NO}_{3}$ averaged absorption spectra measured in the cavity, and the results of their multilinear fit (Eq. 6) are presented in the upper panel of figure 5. The $\mathrm{NO}_{3}$ and averaged spectra of the mixture exhibited a strong distortion of the baseline due to the presence of ozone, as previously mentioned in section 2. Since the $\mathrm{O}_{3}$ absorption cross-section is smooth in this spectral domain (fig. 2), the baseline was easily corrected by a third order polynomial in the fitting model. It should be noted that in usual environmental conditions, ozone concentration will be well below that of our mixture. For example the peak concentration of ozone in Paris during August $1998\left(340 \mu \mathrm{g} / \mathrm{m}^{3}\right)$ would have produced an absorption below $2.5 \times 10^{-8} \mathrm{~cm}^{-1}$ between 610 and $640 \mathrm{~nm}$. So the baseline would have been less affected by the presence of ozone than in the experiments presented here where ozone absorption is above $10^{-7}$ $\mathrm{cm}^{-1}$ when $\mathrm{NO}_{3}$ is produced. Here, the concentrations obtained from the data processing are $183 \pm 10 \mathrm{pptv}$ for $\mathrm{NO}_{3}, 119 \pm 10$ ppbv for $\mathrm{NO}_{2}$ and $184 \pm 10$ pptv for $\mathrm{NO}_{3}$ for the mixture, and $870 \pm 10$ ppbv for $\mathrm{NO}_{2}$. The latter concentration is then in good agreement with the expected $\mathrm{NO}_{2}$ concentration ( $869 \mathrm{ppbv}$ ) fixed by the dilution ratio of the calibrated sample in dry nitrogen.

The residuals of the $\mathrm{NO}_{2}, \mathrm{NO}_{3}$ and mixture spectra fits are plotted in the lower panel of figure 5. The standard deviations are very similar: $3.45 \times 10^{-9} \mathrm{~cm}^{-1}$ for $\mathrm{NO}_{2}, 3.52 \times 10^{-9} \mathrm{~cm}^{-1}$ for $\mathrm{NO}_{3}$ and $3.85 \times 10^{-9} \mathrm{~cm}^{-1}$ for the mixture. This shows that the performance of the system is equivalent for both molecules.

The Allan standard deviation has also been used to study long term stability in the case of simultaneous measurements of $\mathrm{NO}_{2}$ and $\mathrm{NO}_{3}$. Concentrations of these species during this experiment were quite high for trace measurements, $300 \mathrm{ppbv}$ for $\mathrm{NO}_{2}$ and more than 600 pptv for $\mathrm{NO}_{3}$. To produce so much $\mathrm{NO}_{3}$, there was a great amount of ozone in the cell. Consequently, the absorption baseline was much affected by the presence of ozone. Moreover, during the experiment, the $\mathrm{NO}_{3}$ concentration was not stabilized. It was always increasing whereas $\mathrm{NO}_{2}$ concentration did not change as shown in Fig. 6. Therefore the Allan standard deviations of the $\mathrm{NO}_{3}$ concentration is decreasing during only $100 \mathrm{~s}$ whereas the minimum is not reached for $\mathrm{NO}_{2}$. In spite of these difficult measurement conditions, the detection limit for $\mathrm{NO}_{2}$ is just a little more than 1 ppbv in $400 \mathrm{~s}$. Moreover a detection limit of 3 pptv is demonstrated for $\mathrm{NO}_{3}$ in $100 \mathrm{~s}$. The actual detection limit is probably

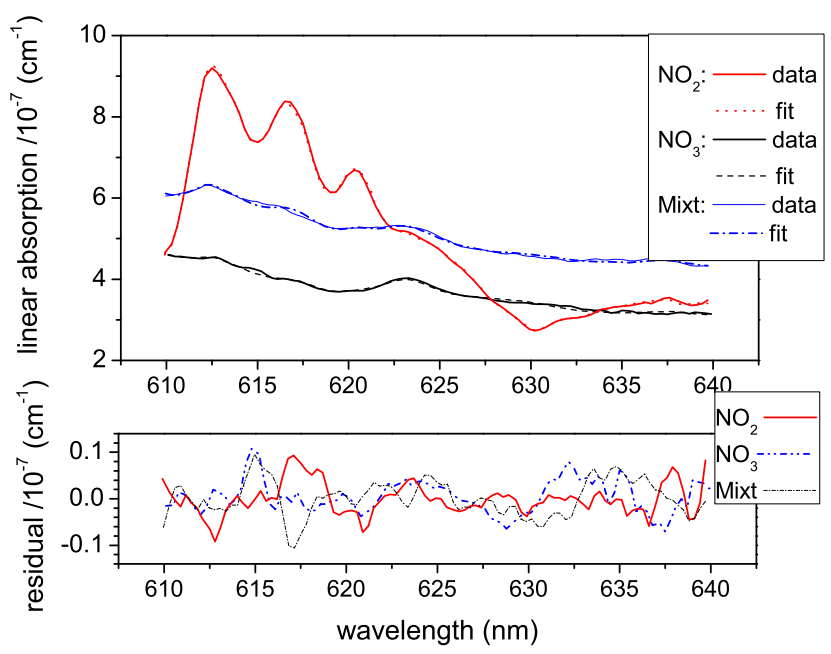

Fig. 5 Multi-linear fit of the linear absorption in the cavity considering $\mathrm{NO}_{2}$ and $\mathrm{NO}_{3}$ absorptions from $610 \mathrm{~nm}$ to $640 \mathrm{~nm}$. The concentrations deduced from the fit are $870 \mathrm{ppbv}$ for $\mathrm{NO}_{2}, 183 \mathrm{pptv}$ for $\mathrm{NO}_{3}$, and respectively $119 \mathrm{ppbv}$ and 184 pptv for the mixture of $\mathrm{NO}_{2}$ and $\mathrm{NO}_{3}$.

lower than the one measured here since the concentration of $\mathrm{NO}_{3}$ was not stabilized during this experiment.
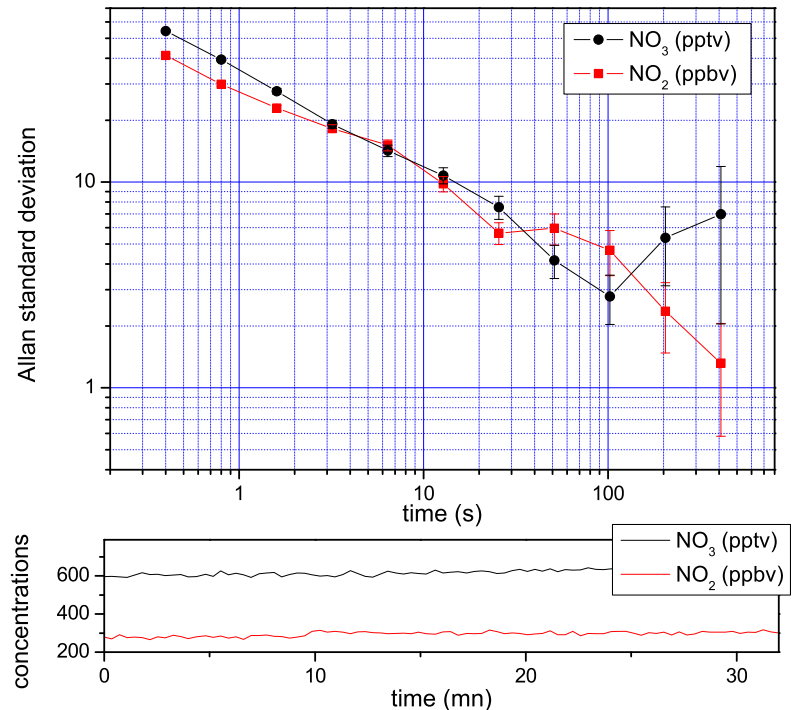

Fig. 6 Allan standard deviations for $\mathrm{NO}_{2}$ and $\mathrm{NO}_{3}$ concentrations measured on a stable flow produced as described in the text. The lower panel shows the evolution of the measured $\mathrm{NO}_{2}$ and $\mathrm{NO}_{3}$ concentrations in the flow.

It is also possible to deduce the detection limit that should be obtained for $\mathrm{NO}_{3}$ measurements by averaging, from the $\mathrm{NO}_{2}$ measurements reported in the previ- 
ous section. Considering that the $\mathrm{NO}_{3}$ spectral structure used by the fitting process corresponds to about $90 \%$ of the total absorption spectrum of this molecule in the given spectral range, a detection limit of $2.3 \times 10^{-10}$ $\mathrm{cm}^{-1}$ is expected in about $400 \mathrm{~s}$. According to the mean value of the $\mathrm{NO}_{3}$ cross section $\left(4.45 \times 10^{-18} \mathrm{~cm}^{2}\right)$, this corresponds to a detection limit of $2 \mathrm{pptv}$ which is in agreement with figure 6 if we extrapolate to $400 \mathrm{~s}$ the decreasing Allan variance.

In the laboratory, the limit of detection for $\mathrm{NO}_{3}$ and the determination of the concentration of the mixture of $\mathrm{NO}_{2}$ and $\mathrm{NO}_{3}$ were degraded by the strong absorption of $\mathrm{O}_{3}$. In future field measurements, the absence or the lower concentration of $\mathrm{O}_{3}$ will not affect the baseline and the measurements of $\mathrm{NO}_{2}$ and $\mathrm{NO}_{3}$ will be possible under more optimal signal conditions, which should lead to improvement in the detection limits.

\section{Conclusion and perspectives}

We have demonstrated that the IBB-CEAS technique can be applied to the detection of $\mathrm{NO}_{2}$ and $\mathrm{NO}_{3}$ traces with a compact, simple and low cost apparatus using a red LED as the emission source. We implemented a data analysis scheme for direct processing of spectral measurements to provide simultaneous real time analysis of both $\mathrm{NO}_{2}$ and $\mathrm{NO}_{3}$ concentrations in a flowing atmospheric sample. A linearity better than $10 \%$ was observed over two decades of $\mathrm{NO}_{2}$ concentrations. It was shown that the absorption sensitivity is the same for both $\mathrm{NO}_{2}$ and $\mathrm{NO}_{3}$, corresponding to a minimum detectable absorbance of $2 \times 10^{-10} \mathrm{~cm}^{-1}$ achieved in about $400 \mathrm{~s}$ averaging. In terms of concentration the detection limit is $600 \mathrm{pptv}$ for $\mathrm{NO}_{2}$ and $2 \mathrm{pptv}$ for $\mathrm{NO}_{3}$. Response time and sensitivity of our instrument are therefore largely adequate to monitoring urban concentrations of these molecules. In particular, the higher sensitivity for $\mathrm{NO}_{3}$ is an interesting feature since its typical concentrations in the environment are 3 orders of magnitude lower compared to those for $\mathrm{NO}_{2}$.

The observed short term noise level is limited by photon shot noise and the best detection limit with data averaging is hampered by the stability of our EPP2000 Stellar Net spectrometer. Significant improvements can thus be implemented in order to enhance the acquisition rate and to allow averaging over longer times. Preliminary tests already demonstrated that it would be interesting, for example, to use a CCD sensor with a better quantum efficiency and a stabilized temperature. By using a fibered spectrograph equipped with a backilluminated CCD, the exposure time for filling the CCD can be reduced by a factor of ten [20]. The use of a more powerful LED would also push down the detection limit. Recently, LEDs emitting in the same spectral region became available with a power of several Watts, more than ten times compared to the LED used for this study.
Finally, this system can also be used to determine dinitrogen pentoxide $\left(\mathrm{N}_{2} \mathrm{O}_{5}\right)$ concentrations following the same scheme as other similar instruments measuring $\mathrm{NO}_{3}[11,12]$. Indeed, by heating the measurement cell to $80^{\circ} \mathrm{C}, \mathrm{N}_{2} \mathrm{O}_{5}$ can be converted to $\mathrm{NO}_{3}$ by the reaction:

$$
\mathrm{NO}_{2}+\mathrm{NO}_{3}+\mathrm{M} \rightarrow \mathrm{N}_{2} \mathrm{O}_{5}+\mathrm{M} \text {. }
$$

To retrieve $\mathrm{N}_{2} \mathrm{O}_{5}$ concentration, it is necessary first to determine the $\mathrm{NO}_{3}$ concentration, then heating the cell measurement to $80^{\circ} \mathrm{C}$ to measure $\mathrm{N}_{2} \mathrm{O}_{5}+\mathrm{NO}_{3}$ concentrations. The minimal $\mathrm{N}_{2} \mathrm{O}_{5}$ uncertainty is the sum of uncertainties of $\mathrm{N}_{2} \mathrm{O}_{5}+\mathrm{NO}_{3}$ and $\mathrm{NO}_{3}$ concentrations. With this method, the expected detection limit will be around 5 pptv in ten minutes measurements for the whole cycle. This detection limit would be better than the 76 pptv expected in Wood et al[11] and higher than the detection limit of $0.5 \mathrm{pptv}$ reported in the work of Brown et al[12]. So this inexpensive, robust and mobile instrument has an important potential and is well suited for $\mathrm{NO}_{x}$ monitoring e.g. in a urban atmosphere.

\section{References}

1. P. J. Crutzen, Quart. J. Roy. Soc. 96, 320 (1970)

2. R. P. Wayne, Chemistry of atmosphere (Oxford University Press, Oxford 2000).

3. T. Stacewicz, P. Wasylczyk, P. Kowalczyk, M. Semczuk, European Journal of Physics 28, 789-796 (2007)

4. data available at www.airparif.asso.fr

5. T. B. Ryerson, E. J. Williams, F. C. Fehsenfeld, Journal of Geophysical Reasearch 105, 26447-26461 (2000)

6. D. Grosjean, J. Harrison, Environmental Science Technology, 19, 862-865 (1985)

7. F. Heintz, U. Platt, H. Flentje, R. Dubois, Journal of Geophysical Reasearch 101, 22891-22910 (1996)

8. U. Platt, Phys. Chem. Chem. Phys., 1, 5409-5415 (1999)

9. K. W. Rothe, U. Brinkmann, H. Walther, Appl. Phys., 4, 181-182 (1974)

10. H. J. Kölsch, P. Rairoux, J. P. Wolf, L. Wöste, Appl. Opt., 28, 2052-2056 (1989)

11. E. C. Wood, P. J. Wollldridge, J. H. Freese, T. Albrecht, R. C. Cohen, Environ. Sci. Technol. 37, 5732-5738 (2003)

12. S. S. Brown, H. Stark, S. J. Ciciora, R. J. McLaughlin, A. R. Ravishankara, Review of scientific instruments 73, 3291-3301 (2002)

13. I. Courtillot, J. Morville, V. Motto-Ros, and D. Romanini, Appl. Phys. B 85, 407-413 (2006)

14. P. L. Kebabian, W. A. Robinson, A. Freedman, Review of scientific instruments 78, 1-9 (2007)

15. S. E. Fiedler, A. Hese, and A. A. Ruth, Chem. Phys. Lett. 371, 284 (2003)

16. S. M. Ball, J. M. Langridge, R. L. Jones, Chemical Physics Letters 398, 68-74 (2004)

17. D.S. Venables, T. Gherman, J. Orphal, J. C. Wenger, and A. A. Ruth, Environ. Sci. Technol 40, 6758 (2006)

18. J. M. Langridge, S. M. Ball, R. L. Jones, Royal Soceity of Chemistry 131, 916-922 (2006)

19. T. Gherman, D. S. Venables, S. Vaughan, J. Orphal, A. A. Ruth, Environ. Sci. Technol. 42, 890-895 (2008) 
20. M. Triki, P. Cermak, G. Méjean, D. Romanini, Applied Physics B 91, 195-201 (2008)

21. T. Wu, W. Zhao, W. Chen, W. Zhang, X. Gao, Applied Physics B 94, 85-94 (2009)

22. S. E. Fiedler, A. Hese, U. Heitmann, Review of scientific instruments 97 10996-11000 (1993)

23. R. Atkinson, D. L. Bauch, R. A. Cox, J. N. Crowley, R. F. Hampson, R. G. Hynes, M. E. Jenkins, M. J. Rossi, J. Troe, Atmos Chem. Phys. 4 1461-1738 (2004)

24. S. Voigt, J. Orphal, J. Burrows, J. Photochem. Photobiol. A 149, 1-7 (2002).

25. D. Allan, Proc. IEEE 54, 221 (1966). 